\title{
A construção da identidade internacional argentina por Estanislao Zeballos nas páginas da Revista de Derecho, Historia y Letras.
}

\author{
The construction of the Argentinian international identity by \\ Estanislao Zeballos in the pages of Revista de Derecho, Historia $y$ \\ Letras
}

\section{Camila Bueno Grejo*}

RESUMO

Os intelectuais argentinos do final do século XIX e início do XX refletiam, de forma obstinada, acerca de seus país, buscando delinear as características nacionais como um meio de justificar a importância da Argentina enquanto um Estado Nacional recentemente constituído diante das transformações econômicas e sociais acarretadas pelo grande afluxo de imigrantes europeus. A busca por elementos que identificassem a nação, ressaltando suas particularidades diante do co nfronto com o estrangeiro e sua importância no continente americano foram questões fundamentais neste período e emblemáticas para a Revista de Derecho, Historia y Letras, fundada e dirigida por Estanislao Zeballos. Nesteartigo, buscamos refletir acerca da importância de Zeballos e de sua Revista, especialmente em relação à construção de uma identidade internacional argentina.

Palavras-chave: Argentina. Identidade internacional. Zeballos. Revista de Derecho. Historia y Letras. Imprensa.

\section{ABSTRACT}

Argentine intellectuals of the late nineteenth and early twentieth centuries stubbornly reflected on their country, seeking to delineate national characteristics as a means of justifying the importance of Argentina as a newly constituted National State in the face of the economic and social transformations entailed By the large influx of European immigrants. The search for elements that identify the nation, highlighting its particularities in the confrontation with the foreigner and its importance in the American continent are issues that have become fundamental in this period and that are emblematic for the Revista de Derecho,

"Doutora em História pela UNESP/Assis e docente do Departamento de História da Universidade Estadual de Londrina. Este artigo é fruto da pesquisa de doutoramento que recebeu apoio financeiro da Capes. camila_grejo@hotmail.com 
Historia y Letras,. In this article, we seek to reflect on the importance of Estanislao Zeballos and his publication, the Revista de Derecho, Historia y Letras, especially in relation to the construction of an international identity in Argentina.

Keyword: Argentina. International identity. Zeballos. Revista de Derecho. Historia y Letras. Press.

Com a consolidação do Estado nacional argentino, em 1880, a maioria dos dirigentes buscou integrar o país ao mercado mundial que se encontrava em plena expansão. Imigrantes, capitais - sobretudo ingleses - e comércio estavam no centro deste cenário e transformaram a Argentina em protagonista de um dos mais espetaculares processos de expansão da história do capitalismo. O crescimento econômico experimentado no final do século XIX e mantido durante a primeira década do XX inspirou suas autoridades a desempenhar uma missão civilizadora na América Latina, demarcando sua hegemonia sobre a região.

Neste artigo nos propomos a analisar a forma como a Revista de Derecho, Historia y Letras (RDHL) refletiu as relações diplomáticas da Argentina com o Brasil país vizinho que, em várias situações, foi visto como uma ameaça a seus interesses hegemônicos. Defendemos, também, a hipótese de que a Revista foi utilizada por Zeballos para promover a projeção de seu país enquanto uma potência continental, mesmo quando afastado da chancelaria argentina.

\section{Panorama nacional argentino e o surgimento da RDHL}

O historiador argentino Oscar Terán (2009, p. 109) ressaltou que no final do século XIX, os processos de modernização transformaram radicalmente o panorama social, político, econômico e estético, introduzindo novos problemas, preocupações e conflitos. Desde a esfera política, a elite encabeçada pelo presidente Julio Argentino Roca, participava ativamente desse processo, mas, de seu interior, surgiram vozes discordantes, apresentando dúvidas e inquietações em relação ao cenário de modernidade que se desenvolvia na Argentina. Nesse sentido, instaurou-se um paradoxo, pois os políticos e intelectuais do final daquele século, não concebiam outra forma de construir um Estado-nação moderno senão por meio da imigração que conduziria o país rumo ao progresso e ao crescimento econômico. As atenções fora do continente, por sua vez, estavam voltadas para a Europa, sobretudo direcionadas à Grã-Bretanha, e era reativa às pretensões norte-americanas de aumento de influência sobre o hemisfério, sob a égide do pan-americanismo (BUENO, 2003). 
Estanislao Severo Zeballos ${ }^{1}$ era um dos intelectuais que se propunha a pensar os problemas nacionais no momento em que se consolidava, na Argentina, uma nova estrutura econômica e social ${ }^{2}$. Sua maturação pessoal e a construção de sua sociabilidade política coincidem com a afirmação de um grupo dirigente nacional que ocupava o poder desde a década de $1880{ }^{3}$. Participou do cenário político argentino como deputado provincial e nacional, ocupou o cargo de Ministro das Relações Exteriores durante os governos de Juárez Celman ${ }^{4}$, Carlos Pellegrini ${ }^{5}$ e de José Figueroa Alcorta ${ }^{6}$; assumiu, também, a função de Ministro Plenipotenciário no México e nos Estados Unidos, foi membro permanente do Tribunal Internacional de Haia, Decano da Faculdade de Direito da Universidade de Buenos Aires e participou das conferências pan-americanas.

Zeballos excedia a caracterização de um profissional da política, convertendo-se em um homem de ação política. Sua prática enquanto publicista a partir da intervenção em alguns dos debates centrais ou conjunturais, tanto no espaço nacional quanto no provincial, nos permite colocá-lo tanto no lugar de um ator, mas, também, de um testemunho privilegiado das mudanças que se buscavam operar na Argentina do período.

Quando iniciou a publicação da Revista de Derecho, Historia y Letras, em 1898, Zeballos já ocupava uma posição de destaque no cenário político e intelectual argentino e latinoamericano. Esse empreendimento lhe permitiu atuar nas funções de mentor, diretor e investidor, assumindo integralmente os riscos decorrentes durante todo o período de circulação.

Àquela época, os intelectuais argentinos chamavam a atenção para os problemas que afligiam a sociedade e destacavam a necessidade de se forjar uma consciência nacional. Zimmermann (1992, p. 546) assinala que o grande contingente imigratório, a corrupção administrativa, a especulação financeira, a fraude eleitoral, o materialismo e a exagerada opulência dos costumes sociais manifestados naquele período eram identificados, pelos

${ }^{1}$ Natural da província de Santa Fé, foi em Buenos Aires que Zeballos completou seus estudos, atuou no Jornal La Prensa (do qual chegou ao cargo de diretor).

${ }^{2}$ A preocupação coma questão nacional não era uma novidade, haja visto o esforço, décadas antes, de Domingo Faustino Sarmiento, Juan Bautista Alberdi e Bartolomé Mitre.

${ }^{3}$ Sua primeira aparição de destaque no cenário político foi como secretário de Mitre no levante contra Avellaneda, chegando a ser, em 1879, deputado na província de Buenos Aires pelo Centro Popular, uma terceira força política encabeçada por José C. Paz.

${ }^{4}$ Durante o governo de Celman, Zeballos atuou na elaboração do Código de Procedimentos e de Comércio, da lei de criação de colônias agrícolas e da produção de agroindústrias e das normas que regulavam a atividade ferroviária. Participou da busca de soluções para os litígios limítrofes co o Chile. Além disso, correspondências datadas de 1890, trocadas entre os dois políticos e posteriormente publicadas na Revista de Derecho, Historia y Letras, evidenciam a sugestão de Zeballos acerca de uma possível renúncia total do gabinete, com vistas a oxigenar a tensa situação política, o que, de fato, ocorreu.

${ }^{5}$ Nomeado por Pellegrini como Diretor de Correios e Telégrafos, passou a desempenhar um papel -chave em relação ao PAN e à burocracia estatal, uma vez que aperfeiçoou o sistema de informações e utilizou os Correios para apoiar e sustentar as clientelas do PAN. Emjunho de 1892 voltou à função de Ministro das Relações Exteriores até o término do mandato, em outubro daquele mesmo ano.

${ }^{6}$ Zeballos destacou-se, neste período, sobretudo com relação à polêmica gerada por seu envolvimento na questão dos armamentos, fato que levou sua política exterior a ser interpretada como agressiva pelos países vizinhos, especialmente pelo Brasil, acarretando sua saída da chancelaria. 
intelectuais reformistas, como sintomas do declínio generalizado da moral. A Revista de Derecho, Historia y Letras $(R D H L)^{7}$ surgiu, portanto, como um instrumento que buscava, por meio da ação intelectual, transformar as instituições e hábitos políticos do país introduzindo uma política de princípios. Por refletir os problemas e questionamentos de uma época, pode ser tomada como um bom exemplo da tentativa intelectual de intervenção nos assuntos pertinentes à afirmação da nacionalidade argentina desde fins do século XIX.

\section{A Argentina e o panorama internacional}

De acordo com José Paradiso (2005, p. 38), no final do século XIX e início do século XX, enquanto os mercados mostravam o perfil de uma relação privilegiada com a Europa, a agenda diplomática argentina mantinha em posição preponderante o âmbito territorial imediato, já que o país estava envolvido em um conjunto de litígios limítrofes que provocavam fricções com os países vizinhos. Para Paradiso, várias destas questões se arrastavam desde a época da independência e foram se agravando à medida que transcorria a segunda metade do século XIX. Essas disputadas devem ser consideradas como reflexo de um fenômeno não circunscrito ao continente americano, mas associado ao processo de consolidação dos Estados nacionais, em meio a circunstâncias econômicas que valorizavam o recursos naturais de cada país e, por conseguinte, dos respectivos territórios.

A presença argentina no sul patagônico ${ }^{8}$ havia sido conquistada pela Campanha do Deserto $^{9}$ e assegurada durante o governo de Julio Argentino Roca (1880-1886) responsável pela introdução de uma nova e moderna concepção em relação à administração do país e ao exercício das relações internacionais. Roca promoveu a reorganização do exército ${ }^{10}$,

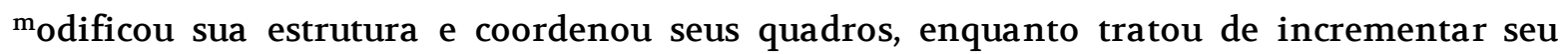
equipamento militar.

A Argentina do início do século XX poderia ser traduzida, portanto, como uma nação orgulhosa e otimista que desfrutava o despertar de um imperialismo do qual, segundo Roberto Etchepareborda (1982), Estanislao Zeballos era o maior representa nte. Na Revista de

\footnotetext{
${ }^{7}$ Foi uma publicação que circulou na Argentina entre os anos de 1898 e 1923, tendo seu término marcado pela morte de Zeballos, seu idealizador, fundador e diretor.

${ }^{8} \mathrm{~A}$ região patagônica incorporada pela Argentina foi alvo de litígio como Chile que reivindicava o direito sobre as terras. A questão parecia solucionada comas negociações de Bernardo de Irigoyen, chanceler argentino, por meio do Tratado de 1881.

${ }^{9}$ Liderada por Julio Argentino Roca enquanto atuava como general no governo de Nicolás Avellaneda, a Campanha do Deserto foi realizada contra as populações indígenas e apoiava-se numa justificativa compartilhada pelas elites do mundo ocidental: que as nações viáveis eram aquelas dotadas de uma população de raça branca e religião cristã. ${ }^{10}$ Até aquele momento, era chamado de Guarda Nacional e funcionava como uma força miliciana.
} 
Derecho, Historia y Letras, Zeballos demonstrava que a questão nacional extrapolava os limites territoriais. Partindo de uma abordagem que contemplava a organização nacional, Zeballos entendia que a afirmação da Argentina enquanto nação soberana não deveria se dar apenas diante dos países americanos, mas, também, das potências europeias.

Estanislao Zeballos percorreu, ao longo de sua vida política e intelectual, uma trajetória de ascensão. Seu envolvimento com as letras, a ciência e a política, o levou a ocupar o disputado Ministério das Relações Exteriores em três oportunidades: nos governos de Juárez Celman (1889-1890), Carlos Pellegrini (1891-1892) e de Figueroa Alcorta (1906-1908), contribuindo para a construção de sua reputação como profundo conhecedor das questões diplomáticas e do direito internacional.

Aos 35 anos de idade já era considerado um dos mais renomados especialistas argentinos em questões diplomáticas e de limites. Sua designação para a chancelaria do governo Celman se deu num momento de reorganização política ${ }^{11}$ em que o chefe do executivo buscava o apoio de Zeballos e de outros jovens e ambiciosos políticos com o intuito de mudar a fachada do oficialismo roquista, fortemente associado ao tradicionalismo provinciano e à astúcia de uma política mesquinha (PAREDES, 2011, p. 113). Roberto Ortigueira (1993, p. xiii), em um texto introdutório à obra La política exterior de Chile, corrobora esta versão e ressalta que, embora jovem, o grande prestígio de Zeballos na área do direito ${ }^{12}$ - especialmente em questões de limites -, relacionava-se ao profundo conhecimento que possuía em geografia e história colonial hispano-americana.

Zeballos não militou organicamente em nenhum partido político e não estava voltado especificamente a nenhum dos grupos políticos que dominavam o cenário argentino, além disso, não mantinha uma relação plena com os dirigentes que os representavam. Nesse contexto, seu primeiro mandato à frente do Ministério das Relações Exteriores era frágil. Manifestava respeito pessoal pela figura de Bartolomé Mitre ${ }^{13}$ e, em relação a Roca, ainda que no início de sua carreira política o tivesse admirado pela Campanha do Deserto e por sua gestão progressista, houve um rompimento político em 1885 quando o então presidente se opôs à pretendida candidatura de Zeballos para o governo de Santa Fé.

O grande foco da primeira passagem de Zeballos pela chancelaria argentina foi a condução das negociações diplomáticas com o Chile. Como forma de preservar as conquistas territoriais, o ministro resolveu, por meio de um decreto ministerial, em 20 de novembro de 1889, que a partir dessa data, todos os mapas e cartas geográficas do território argentino

\footnotetext{
11 Zeballos substituiu Norberto Quirno Costa - ex vice-presidente durante o governo de Roca - que passou à frente do Ministério do Interior, já que o titular, Wenceslao Pacheco, retornou ao Ministério da Fazenda

12 Sua notoriedade se deu em virtude da defesa que realizou dojornal La Prensa em resposta a uma ação movida pelo governo de Buenos Aires, cuja defesa fora baseada na liberdade de imprensa.

13 Apesar de não concordar com a tendência conciliadora manifestada em seu apoio à política do acordo.
} 
anteriores a ele eram ilegítimos ${ }^{14}$. Com esta medida, buscava evitar que os países adversários pudessem utilizar os mapas produzidos no país ${ }^{15}$ para fundamentar pretensões expansionistas que incorporassem o território argentino (ORTIGUEIRA, 1993, p. xiv).

Em segunda gestão no Ministério Exterior, durante o governo de Carlos Pellegrini, Zeballos não mais necessitava de apoio explícito para ter participação nas decisões governamentais. Buscou organizar toda a documentação relativa à questões de limites, pois constatou que ela estava exposta livremente, sem nenhum tipo de controle ou segurança e, demonstrando preocupação com a manutenção das fronteiras e, por conseguinte, com a soberania nacional, ordenou o envio de importantes documentos para arquivos europeus, onde acreditava que estivessem mais seguros. Criou, também, a Oficina de limites internacionais, voltada ao estudo de problemas limítrofes, cuja função era investigar antecedentes de questões geográficas, históricas, topográficas e diplomáticas; além disso, fez parte de suas atribuições, o envio de uma comissão, liderada por José de Orellana, para Sevilha com o intuito de recompilar toda a documentação de antecedentes coloniais referente a limites e jurisdições existente no Arquivo de Índias ${ }^{16}$. A criação de uma biblioteca especializada em questões limítrofes e em história diplomática latino-americana foram, também, realizações da gestão de Zeballos.

Não obstante, sua atuação na chancelaria foi interpretada por muitos como imperiosa e conflitiva, especialmente em relação a questões que envolviam o Chile e o Brasil em um contexto dominado pela definição de limites a nível local e por alianças continentais a nível internacional, marcando a inserção da Argentina em uma arriscada disputa pela influên cia na porção sul do continente americano.

A $R D H L$ refletia estes ideais e buscava dar significado à nação a partir de discussões sobre assuntos políticos internos, mas, também, externos. Dessa forma, estabelecia a identificação da nação argentina a partir de sua importância diante dos "outros" que poderiam ameaçar sua soberania. A construção da identidade nacional argentina estava vinculada, portanto, à constituição do eu (argentinos), do nós (representados pelos imigrantes e seus filhos) e dos outros (as demais nações).

\footnotetext{
14 Essa determinação incluía os mapas e cartas cartográficas publicados com autorização oficial anteriores a 20 de novembro de 1889.

15 Muitos destes mapas continham erros de traçado e demarcação de territórios que não havi am sido enunciados anteriormente.

16 Zeballos teria ordenado que os pesquisadores averiguassem se agentes de outras nações teriam buscado por documentos argentinos.
} 


\section{O Brasil e a ameça aos planos hegemônicos argentinos}

Brasil e Argentina mantinham uma atenção recíproca prioritária que não se baseava apenas em desavenças fronteiriças, mas em uma atitude preventiva ligada a questões de equilíbrio regional, alimentadas, segundo a perspectiva de Paradiso (2005, p. 52), por um legado histórico herdado da antiga rivalidade luso-espanhola.

Boris Fausto e Fernando Devoto (2004, p. 227) caracterizam o campo das relações internacionais dos dois países como uma dupla via com ligações entre si, formada, de uma parte, pelo papel desempenhado no mundo e, de outra, pela posição de cada um deles no continente americano, especialmente no Cone Sul. Para os autores, Brasil e Argentina apresentavam muitas semelhanças na posição ocupada no contexto internacional, pois eram países periféricos com escassas possibilidades de encontrar um espaço ao lado das potências. A Argentina estava ligada ao capital inglês na área do comércio exterior, dos investimentos e dos empréstimos internacionais, enquanto o Brasil, nas últimas décadas do Império, realizava uma política de gradativa aproximação com os Estados Unidos, país que demonstrava, cada vez mais, seu interesse em desempenhar um papel hegemônico na América e ter maior presença no cenário mundial.

A proclamação da República dos Estados Unidos do Brasil, em 1889, contou com o rápido reconhecimento por parte da vizinha Argentina que àquela época, tinha Estanislao Zeballos à frente do Ministério do Exterior. Como chanceler do governo Pellegrini, firmou com Quintino Bocaiuva, ministro das relações exteriores brasileiro, um acordo bilateral para a definição de limites na litigiosa região de Misiones-Palmas. O objetivo era impedir a amputação de uma faixa de território considerado brasileiro, ao longo do oeste de Santa Catarina, o qual era essencial para o Brasil por razões de segurança e para a comunicação do rio Grande do Sul com o restante do país (FAUSTO; DEVOTO, 2004, p. 231).

A proclamação da República no Brasil (1889) e o rápido reconhecimento por parte da Argentina contribuíram para um clima de confraternização entre os dois países que assinaram, em 1890, o Tratado de Montevidéu que partilhava o território disputado sem a necessidade de arbitragem. Este acordo, entretanto, provocou protestos violentos do Exército e da Marinha brasileiros e não foi ratificado pela maioria na Câmara dos Deputados $^{17}$, inaugurando uma nova fase nas negociações diplomáticas entre os dois países (PAREDES, 2011).

A Argentina concordou com a volta do princípio da arbitragem e, em 07 de setembro de 1889, Zeballos, designava Nicolás A Calvo como defensor dos interesses argentinos e ao

${ }^{17}$ Situação apontada por Zeballos como resultado da influência chilena sobre o Brasil. 
presidente dos Estados Unidos, Grover Cleeveland, como responsável pela elaboração do laudo arbitral. O inesperado falecimento de Calvo, em maio de 1893, levou à nomeação de Zeballos $^{18}$, enquanto o Brasil constituiu José María da Silva Paranhos, o Barão do Rio Branco, como artífice de sua defesa. O laudo do presidente Cleaveland foi apresentado em 5 de fevereiro de 1895 e mostrou-se favorável ao argumento brasileiro ${ }^{19}$. De acordo com José Paradiso (2005), as desavenças das décadas de 1870 quase levaram os dois países a um conflito armado, acentuaram as discórdias e fortaleceram a posição de confronto entre eles. Para o autor, o litígio com o Chile adiou esse antagonismo, deslocando a atenção argentina para a fronteira andina.

O fracasso diplomático e o período que viveu nos Estados Unidos marcaram um novo momento na carreira política e intelectual de Zeballos, evidente a partir de sua ruptura com Julio Argentino Roca e seus seguidores. Ao retornar à Argentina, em 1896, passou a articular uma nova campanha no campo político e diplomático contra Roca - que se lançava para as disputas presidenciais de 1898 -, por meio de seu mais importante instrumento de ação política e intelectual: a Revista de Derecho, Historia Y Letras.

A partir de suas páginas evidenciamos uma importante mudança nas ideias sustentadas por Zeballos a respeito de diplomacia, guerra e território. Segundo a perspectiva de Rogelio Paredes (2011, p. 115), as inquietações pelo conhecimento geográfico e genericamente científico que Zeballos havia evidenciado no início de sua carreira política ${ }^{20}$ deram lugar a influências marcadas pela política de alianças e hostilidades que a França e a Alemanha desenvolviam desde o Tratado de Frankfurt, de $1871^{21}$ e que o inspiraram a um alinhamento diplomático entre a Argentina e a recém-proclamada República Brasileira. Contudo, o fracasso na negociação de limites na região de Misiones-Palmas e o resultado desfavorável do laudo arbitral de Cleveland, levou Zeballos a buscar novos modelos para compreender a situação continental da Argentina que, de seu ponto de vista, se opunha ao bloco brasileiro chileno, contra o qual deveria empreender, inevitavelmente, um conflito decisivo pelo controle da região.

\footnotetext{
${ }^{18}$ Como ministro extraordinário do governo argentino nos EUA, Zeballos se instalou em Washington por um período de dois anos, enquanto preparou a tese de defesa argentina na questão de Missiones-Palmas.

${ }^{19}$ Moniz Bandeira afirma que a inclinação dos Estados Unidos pelo Brasil deveu-se a razões de afinidades políticas e econômicas. Ver: Bandeira (2003).

${ }^{20}$ Concepções que contribuíram para a publicação de obras como La Conquista de las quince mil léguas (1878) e Viaje al país de los araucanos (1881).

${ }^{21} \mathrm{O}$ Tratado de Frankfurt pôs fimà guera franco-prussiana e converteu a Alemanha em uma grande potência europeia.
} 


\section{Visitas presidenciais e a reaproximação diplomática}

Na virada do século XX, Brasil e Argentina estreitaram laços de amizade e cooperação. As edições da $R D H L$, publicadas nos meses de outubro e novembro de 1900, dispensaram especial atenção ao Brasil por meio de inúmeros artigos ${ }^{22}$ que marcavam a ruptura política ocorrida no país vizinho, mas, também, rendiam homenagens à monarquia findada. $\mathrm{O}$ soneto intitulado "O adeus" ${ }^{23}$, da autoria de D. Pedro II fora escolhido para abrir a edição da $R D H L$ dedicada à consagração da fraternidade entre a Argentina e o Brasil e buscou destacar a boa relação mantida entre os dois países enquanto vigorou o império brasileiro. A publicação apresentou, também, uma compilação de dados que funcionou como um resumo histórico das mudanças ocorridas no Brasil após $1889^{24}$, além de uma seção que trazia os provérbios mais utilizados pelos brasileiros e homenagens a figuras políticas como General Osório e Quintino Bocaiuva.

Durante a segunda gestão do governo Roca, portanto, as relações entre Brasil e Argentina mantiveram um certo nível de concordância, evidenciado pela troca de visitas entre ele e Campos Sales, afirmando a simpatia entre os dois países (BUENO, 2003, p. 170). $\mathrm{Na} R D H L$, a proximidade e os laços de amizade entre os vizinhos sul-americanos tiveram destaque:

La crisis del Brasil es honda y persistente. Una quincena, varias, no bastarán para dominrla; de manera que la visita del Presidente Campos Sales tiene para nosostros méritos excepcionales que la República Argentina reconoce y con mayor efusión, si cabe, agradece, al aclamar al noble varón y alto magistrado de la República amiga y vecina, huésped de la tierra libre, hospitalaria y justa del plata. (ZEBALLOS, 1900a, p. 139).

Zeballos ressaltou o esforço do presidente brasileiro em visitar a Argentina em um momento de dificuldades econômicas para o Brasil ${ }^{25}$, dedicou várias páginas de sua revista a

\footnotetext{
${ }^{22}$ Os textos haviam sido escritos por brasileiros e contaram com a tradução de Zeballos.

${ }^{23}$ De acordo com a nota explicativa de Zeballos, D. Pedro II escreveu o soneto enquanto realizava a viagem de volta a Portugal após a proclamação da República Brasileira.

${ }^{24}$ Os dados apresentados diziam respeito à população brasileira, ao território do país, às rendas e gastos do governo, aos Estados que eram governados por bacharéis em direito, além de análises quantitativas de deputados senadores por estados e quantas e quais eram as estátuas erigidas a próceres.

${ }^{25}$ As dificuldades apontadas por Zeballos estavam relacionadas à queda dos preços do café, principal produto de exportação brasileiro, temática que ganhou atenção especial na edição de novembro de 1900.
} 
homenagens a figuras políticas vinculadas ao novo governo e registrou as palavras proferidas por Roca e Campos Sales no banquete realizado no palácio argentino em homenagem à comitiva brasileira, pois, segundo ele, jamais havia ocorrido na América do Sul expectativa tão intensa e solene:

El Brasil, la Argentina, Chile, el Perú, Bolivia, el Ecuador, el Paraguay y el Uruguai de una manera inmediata y las outras naciones com menos fervor, aguardaban la palavra de los presidentes Campos Sales y Roca em el banquete del Palacio argentino, para pesar profundamente cada una de sus frases políticas .(ZEBALLOS, 1900b, p. 157).

A visita de Campos Sales foi uma retribuição à ida de Julio A. Roca ao Brasil no ano anterior e contribuiu para uma franca aproximação entre os países por eles representados. Fausto e Devoto (2004, p. 231) explicam esse entendimento a partir do quadro de tensas relações, naqueles anos, entre a Argentina e o Chile, em que o Brasil não tomou partido ${ }^{26}$, adotando uma posição de neutralidade e afirmando sua disposição de atuar como intermediário, em busca de um relacionamento pacífico. Acerca disso, Moniz Bandeira (1973) observa que a Argentina sempre temeu e evitou cair em uma situação que a deixasse política e militarmente comprimida entre o Brasil e o Chile, o que a levaria a lutar em duas frentes, em caso de guerra, com resultados catastróficos previsíveis. Assim, as relações de maior tensão ou de relativa aproximação entre a Argentina e o Chile tinham muito a ver com a postura respectivamente mais ou menos amistosa desse país relativamente ao Brasil (FAUSTO; DEVOTO, 2004, p. 232).

\section{A lei de armamentose a reativação das disputas}

As disputas entre Brasil e Argentina se reativaram a partir da sanção da lei dos armamentos navais no Brasil, em 1904, que causou grande comoção em Buenos Aires. O programa naval elaborado pelo almirante Júlio César de Noronha, Ministro da Marinha brasileira, compreendia a compra de navios, cujos modelos eram os das melhores esquadras da época e fora motivado, sobremaneira, pela vitória do Japão sobre a Rússia (1904-05) em

\footnotetext{
26 Zeballos fazia questão de destacar queo Chile havia realizado tentativas de cooptar o apoio brasileiro, porém, sem
} sucesso. 
uma guerra decidida nos mares e que exerceu forte influência sobre países ${ }^{27}$ interessados em modernizar suas armadas com embarcações de grande porte (BUENO, 2003, p. 183-184). O argumento do ministro Noronha residia na comparação com o Chile que, entre 1891 e 1900, havia investido na renovação de sua marinha de guerra, e justificava o incremento naval brasileiro a partir de uma estratégia de defesa ${ }^{28}$.

A Argentina, por sua vez, estava condicionada pelos Pactos de Maio ${ }^{29}$ (1902), que determinavam sua equivalência naval com o Chile, situação que contribuiu, para que ecoassem no país, denúncias acerca da insuficiência de sua defesa e da urgência na adoção de medidas para o reequipamento militar com vistas a impedir a supremacia naval do país vizinho (PARADISO, 2005, p. 55).

Desde 1902, a chancelaria brasileira era ocupada por Rio Branco ${ }^{30}$ que desempenhou a função até 1912, ano de sua morte. Na primeira década republicana, o Brasil havia carecido de uma diretriz norteadora de sua política externa e perdeu rapidamente a credibilidade internacional que havia conquistado no Segundo Império (MUÑOZ, 2010, p. 47) e o Barão assumiu a pasta das relações exteriores visando a recuperação da imagem internacional do Brasil.

Zeballos logo se manifestou a respeito da lei de armamentos brasileira. Para ele, tra tavase de uma questão de Estado e afirmava compreender as motivações brasileiras apresentadas pelo periódico carioca $O$ Paiz $^{31}$, segundo as quais, o Brasil precisava de uma esquadra que satisfizesse suas aspirações legítimas e nobres. Conforme havia sido especulado pelo Jornal do Commercio, existia a expectativa de que Zeballos tomasse a iniciativa de uma campanha contrária à nova lei brasileira; contudo, em sua Revista, fez questão de ressaltar a postura de aproximação e cordialidade sincera entre os doi s países:

Pienso hoy, como en 1889 y en 1892 en el ministério de relaciones exteriores, que hay conveniencias fundamentales, diplomáticas y

\footnotetext{
${ }^{27}$ A guerra russo-japonesa teve grande repercussão na RDHL que dedicou amplo espaço à análise do conflito. ${ }^{28}$ Noronha e a Marinha brasileira seguiam a doutrina criada pelo almirante Alfred Mahan, da Marinha norte-americana, que preconizava a necessidade de forças navais de um país terem esquadra capaz de, atuando reunida, disputar ao inimigo, em batalha decisiva, o domínio do mar.

${ }^{29}$ Assinados em 1902, com o Chile, os Pactos de Maio determinavam a equivalência naval entre a Argentina e o Chile, o que a impedia de arregimentar seu programa naval.

${ }^{30}$ A primeira desavença entre Zeballos e Rio Branco ocorreu em 1875 , quando o enviado especial argentino no Rio de Janeiro, Carlos Tejedor, retornou à Argentina sem se despedir do Imperador. Na ocasião, o futuro Barão do Rio Branco defendeu, pelas páginas de $A$ Nação, que não houve "nenhuma ofensa internacional ao Brasil. Houve apenas uma gaucherie". Em Buenos Aires, os ânimos se exaltaram. Zeballos, através do jornal Nacional, respondeuao jovem Paranhos, traduzindo erroneamente gaucherie como gauchada, afirmando: "Umdos diários mais importantes do Brasil qualificou de gaucherie a retirada do Sr. Tejedor. Este modo de se exprimir não é mais do que uma macacada de má lei. E melhor ser gaúcho do que macaco." Coma Questão de Misiones-Palmas, resolvida em 1895, havia se iniciado um novo período de embates entre os dois personagens que se estendeu até 1912, com a morte de Rio Branco.

${ }^{31}$ Zeballos se mostrou simpático ao jornal $O$ Paiz, que geralmente lhe tecia elogios; já em relação ao Jornal do Commercio apresentava ressalvas.
} 
económicas que aconsejan esta solidariedad de las dos naciones. Ellas tienen la rsponsabilidad del éxito de los anhelos de civilización y de libertad en Sur América. Ellas serán las grandes potencias continentales del hemisferio sur antes de cincuenta años. [...]. Soy, pues, amigo convencido y resuelto del Brasil. (ZEBALLOS, 1904, p. 293).

Diante do exposto, Zeballos se voltou a buscar explicações para a compra de armamentos empreendida pelo Brasil e apontou as razões que considerava já ser conhecidas por muitos brasileiros e estrangeiros:

El Brasil necesita reorganizar su poder naval. Para el pueblo del Brasil esta reorganización es, además de necesaria, punto de amor propio nacional!

[...] Una nación como la vecina, cuyas costas marítims corren sobre mil docientas leguas, del Plata hasta las Guayanas, ofrece todo flanco marítimo descubierto al comercio de los países que dominan los mares.

[...] El Brasil siente necesidades supremas de seguridad y de vida externa e interna que no pueden ser satisfechas sino por medio de una marina de guerra eficiente. El Brasil ha sido, debe ser y será siempre una potencia naval! (ZEBALLOS, 1904, p. 294).

O autor concordou, portanto, com a necessidade de armamentos para proteção costeira e defesa territorial, mas ressaltou que a satisfação dessa necessidade deveria adotar uma medida razoável que, segundo Zeballos, escapava à observação do governo brasileiro. Considerou como excessiva a quantidade de armamentos que, conforme afirmara o próprio Rio Branco, respondia ao objetivo de defesa e conservação.

A conclusão de Estanislao Zeballos era a de que o Brasil buscava constituir uma força superior a todas as frotas sul-americanas reunidas, a qual poderia vir a ocupar o sétimo lugar entre as potências marítimas mundiais. De acordo com a interpretação belicista do diretor da $R D H L$, o Brasil se armava para superar a força naval argentina, bastante superior à sua e a mais importante da América do Sul. Contudo, ressaltou que não concebia um propósito de ataque à Argentina, apesar de reconhecer a rivalidade alimentada pelos brasileiros. Em síntese, compreendeu que o Brasil não investia em armamentos com vistas a promover um ataque ao país "amigo", embora percebesse a necessidade de se precaver e 
superá-lo. Neste contexto, Zeballos passou a defender que a Argentina também se armasse, alegando as mesmas razões manifestadas inicialmente pelo Brasil.

Não obstante, argumentava a respeito da necessidade da Argentina demonstrar um posicionamento diante da postura exagerada adotada pelo Congresso brasileiro. Para ele, havia três caminhos diplomáticos possíveis de serem trilhados para a resolução do impasse. O primeiro e preferido por Zeballos, consistia na negociação de um plano de desenvolvimento naval proporcional, econômico e racional que afastasse o perigo recíproco; o segundo residia em convidar o Chile, em nome da lealdade aos Pactos de Maio, a contribuir com a Argentina, realizando pressões sobre o Brasil e forçando seu governo a desistir de lançar a América do Sul em uma nova era armamentista. O terceiro, por sua vez, propunha que fosse denunciado o pacto argentino-chileno - baseado na limitação de armamentos - e que fosse adotado o mesmo critério estabelecido pelo Brasil e ratificado por sua imprensa: a necessidade de proteção.

De fato, o projeto naval brasileiro apresentou-se como um desafio para a Argentina, que se via como a principal potência da região. Conforme afirmou Etchepareborda (1982, p. 82), a política armamentista do Brasil era julgada pelo governo argentino como perigosa e, de algum modo, justificava a prédica de Zeballos, pois representava a ruptura do equilíbrio naval sul-americano; além disso, o argumento de que estes armamentos navais apenas seriam utilizados para proteger a extensa costa brasileira não tranquilizaram os condutores da política argentina ${ }^{32}$.

Na Revista de Derecho, Historia y Letras, Zeballos advogava em favor de um "Destino Manifesto" argentino, noção associada à superação de obstáculos que se impunham à criação da nacionalidade (ETCHEPAREBORDA, 1982, p. 52). Esta expressão foi empregada, pela primeira vez, na $R D H L$, durante um discurso pronunciado por Zeballos no funeral cívico do General Bartolomé Mitre:

[...] los hombres del Plata entraran en acción con un verdadero "destino manifiesto". Dotados de una cultura más clásica que política, todo lo improvisaran: ideas de gobierno, soldados, generales y armamentos, y de triunfo em triunfo fundaron la independencia de Chile, del Uruguay, del Paraguay, de Bolivia, del Perú con sentimientos recíprocos e de civilización. (ZEBALLOS, 1906, p. 78).

\footnotetext{
${ }^{32}$ Sobre esse assunto, ver: Neto (2014) e De Martini (2014).
} 
Ainda com referência a esta ideia, Zeballos sustentou, em 1904, ao defender uma política armamentista para a Argentina que:

La vida de las Naciones modernas no es una Arcadia. Es de choques de intereses, de peligros y de sabias previsiones. Los países que por cobardía del espíritu público o por lirismo de sus estadistas hayan soñado que le es posible vivir fuera de la regla universal, es decir sin armamentos proporcionados, harían bien de abdicar de una vez su soberanía, ingresando como colonias inermes de las grandes potencias. Pero los pueblos viriles, por más mercantiles que sean -Estados Unidos, Alemania e Inglaterra lo enseñan- deben aceptar simultáneamente cargas pecuniarias y la labor que la militarización de los tiempos les imponen, sin más limitaciones que las del criterio nacional, aconsejada por sus recursos y por sus necesidades. (ZEBALLOS, 1904, p. 297-298).

Para Zeballos, a Argentina estava destinada a ser uma Nação moderna com um povo viril, mas ele não era o único a professar a superioridade do país. José Ingenieros também o fazia, porém, a partir da superioridade da "raça argentina" explicada, por ele, com base em quatro fatores: a amplitude de seu território, a fertilidade de seu solo, seu clima temperado e sua raça branca. Esses fatores permitiriam que a Argentina superassem Brasil e Chile, seus adversários na região, consolidando, conforme defendia Ingenieros, a influência moral e material da Argentina na América do Sul:

[...] la Historia se burla de los débiles y es cómplice de los fuertes. Sin fuerza no hay derecho, quienes desean reivindicar un derecho, sea un individuo, una nación o una raza, debe trabajar para ser el más fuerte. Eso basta". (INGENIEROS, 1956, p. 120).

Nessa conjuntura, o espírito da época favoreceu o recrudescimento da antiga rivalidade entre as duas maiores repúblicas limítrofes na América do Sul e Zeballos voltou a evocar o "Destino Manifesto argentino" diante daquilo que chamou de Plano de Rio Branco; não obstante, o rearmamento tornou-se um componente da disputa pelo prestígio e contribuiu para criar um ambiente típico de corrida armamentista (BUENO, 2003, p. 197). Assim, entre os anos de 1904 e 1908, a imprensa portenha desenvolveu uma campanha em prol do rearmamento naval que tinha como contraponto o projeto brasileiro. 
Embora a chancelaria brasileira e o Senado tivessem se manifestado acerca do caráter pacífico da reorganização da esquadra, seus argumentos não foram suficientes para conter a imprensa de Buenos Aires. Zeballos era uma figura influente e contava com o apoio de vários jornais ${ }^{33}$, sobretudo La Prensa e La Razón para ecoar as críticas à lei de armamentos brasileira e a defesa de um projeto que previa o aumento da Armada e do Exército de seu país. Conforme demonstra Clodoaldo Bueno (2003), Estanislao Zeballos e o Barão do Rio Branco discutiram por meio dos jornais, mas sempre foi um princípio do ministro brasileiro não permitir nenhum arranhão ao prestígio nacional.

Em 1906, com o falecimento do presidente argentino Manuel Quintana, o vicepresidente José Figueroa Alcorta passou a comandar o país. A partir de então, teve início uma fase de relações tensas entre Buenos Aires e o Rio de Janeiro, principalmente depois que Zeballos assumiu a chancelaria argentina, em novembro do mesmo ano. Bueno (2003, p. 170-171) pondera que eram cordiais as relações entre os dois países no começo da gestão de Rio Branco, principalmente em razão da atuação do presidente Roca e de Manuel Gorostiaga, ministro argentino no Rio de Janeiro que deixou o posto em 1905.

Com Zeballos à frente da chancelaria a discussão a respeito do rearmamento naval argentino atingiu um ponto crucial. $\mathrm{O}$ ministro argentino, para efeitos de política interna, forçou um convite para visitar o Brasil; Rio Branco havia instruído Assis Brasil representante brasileiro em Buenos Aires - para fazer constar que se Zeballos quisesse realizar a visita, que o fizesse por sua própria vontade, pois formular um convite, naquela conjuntura, seria encarado como intimidação e humilhação do governo brasileiro.

Em contrapartida, o convite foi direcionado ao general Julio Roca e a Emilio Mitre, quem, a pedido do presidente F. Alcorta, desembarcou no Rio de Janeiro na volta de uma viagem à Europa. A "chancelaria paralela" desempenhada por E. Mitre tornou-se notícia em vários diários portenhos e foi planejada pelos próprios políticos argentinos que não estavam de acordo com o estilo e os propósitos de Zeballos; a acolhida que Rio Branco ofereceu a Mitre deve ser interpretada, portanto, como uma manobra para desprestigiar seu rival.

Roca visitou o Brasil em março de 1907 e foi recebido com grande entusiasmo pelo presidente Afonso Pena, pelo ex-presidente Campos Sales, pelo ex-ministro das relações exteriores Quintino Bocaiuva, além do próprio Barão do Rio Branco. Durante sua estadia, Roca proferiu um discurso que pregava a aproximação entre a Argentina e o Brasil contrariando a política desenvolvida por Zeballos.

Com o falecimento de Bartolomé Mitre, em 1906, Figueroa Alcorta passou a ser o responsável por emitir o laudo arbitral a respeito do conflito fronteiriço entre o Peru e a

\footnotetext{
${ }^{33}$ Zeballos utilizava os jornais como veículos de divulgação de seus ideais, pois estes tinham um alcance maior que o pretendido com a Revista de Derecho, Historia y Letras e, dessa forma, conseguia atingir a diferentes públicos leitores.
} 
Bolivia $^{34}$. Com isso em mente, Zeballos interpretou as homenagens tributadas a Roca no Brasil como parte do interesse desse país na decisão da questão de limites que seria arbitrada pelo governo argentino.

Nas páginas de sua Revista, Zeballos encarnou, a partir de 1908, uma postura belicista e fomentou uma intensa campanha armamentista sob a justificativa de buscar um equilíbrio com a política desenvolvida pelo Brasil. O artigo intitulado "Resurgimiento cívico. El alma argentina", primeiramente publicado no diário La Prensa, versava acerca do patriotismo que renascia na Argentina diante da controvérsia internacional:

\begin{abstract}
Algo muy argentino llena de orgullo a los espíritus que contemplan serenamente esta alta expresión del patriotismo nacional, y es la cultura, la circunspección, el respeto reinante en esas manifestaciones populares comn relación a la acusa que las motiva; ninguna agresión, ningún descomedimiento por nadie; todos los entusiasmos para la patria, todos los anhelos de seguridad y de grandeza para ella. Esos pueblos no se conmueven sino para servila, para pedir a los poderes públicos, para exigirles que velen por ella, que la resguarden contra toda eventualidad, proveyéndola de los medios de defensa que necesitan su vida, su integridad y su honra. (ZEBALLOS, 1908a, p. 302).
\end{abstract}

A RDHL apresentou, também, trechos de jornais argentinos que se posicionaram e responderam à convocação de Zeballos para as manifestações pró-armamentos. Os periódicos que apoiaram a causa estavam localizados em La Plata, Buenos Aires, Corrientes, Santa Fé e Córdoba, dentre os quais podemos citar: El argentino, El dia de La Plata, La Prensa, La voz del interior, La Capital e La justicia, além de um órgão católico chamado Los princípios, que apoiava a causa e de outro, La libertad, ligado ao Partido Radical, que se opunha ao chamado de Zeballos, mas que, todavia, se manifestou.

O interessante é que a manifestação patriótica pró-armamentos foi o grande destaque da publicação em novembro de 1908, ressaltando o protagonismo de Zeballos nesta ação. Somado às convocações, apareceram as respostas emitidas, por meio da imprensa, de vários grupos - muitos deles compostos por jovens estudantes - e órgãos, acompanhados da transcrição dos discursos proferidos por Zeballos em cada um dos locais que visitou. Além disso, a RDHL adotou uma postura inédita ao publicar fotografias dos principais artífices

\footnotetext{
${ }^{34}$ Muñoz argumenta que a decisão do laudo argentino teria marcada influência sobre o território do Acre, já que este havia sido previamente transferido pela Bolívia ao Brasil e, portanto, uma vitória boliviana no pleito arbitral seria um êxito brasileiro. Por outro lado, se Alcorta desse ganho de causa ao Peru, as relações entre Lima e o Rio de Janeiro, provavelmente, se agravariam. Ver: Muñoz (2010, p. 53).
} 
das manifestações e, de uma em especial, de forma destacada, na qual estavam identificados todos os políticos, intelectuais e homens de prestígio nacional que integraram a comitiva de Zeballos na reunião realizada em Córdoba, que reproduzimos a seguir.

É incontestável que a presença de Zeballos no ministério assinalou um novo momento nas relações diplomáticas argentinas. Sua defesa do rearmamento e da equivalência naval entre o Brasil e a Argentina, nunca foi apresentada, ao governo brasileiro, como uma proposta formal, circunscrevendo sua ação política a debates travados por meio da imprensa. Segundo argumenta Muñoz, Zeballos via em Rio Branco um continuador da diplomacia astuta do Barão de Cotegipe e propôs-se a empregar todos os meios para impedir que o Brasil se rearmasse. Desde os Pactos de Maio (1902), Buenos Aires e Santiago detinham uma discreta equivalência naval e Zeballos procurou a consecução de uma aliança defensiva com o Chile para forçar o Brasil a se adequar a mesma paridade (MUÑOZ, 2010, p. 55). O plano de isolar o Brasil por meio de manobras políticas - tal como ocorria na diplomacia europeia - havia levado Zeballos a recompor as relações com Paraguai e Uruguai, além da fundamental reaproximação com o Chile, para que se apresentassem em conjunto e exercessem maior pressão sobre o Brasil, de forma a fazê-lo desistir de seus objetivos armamentistas. Contudo, a tradicional "amizade" entre estes países frustrou a tentativa do chanceler argentino.

Em junho de 1908, o ministro argentino propôs ao presidente Figueroa Alcorta um plano que previa a exigência de o Brasil dividir seus navios e, até, uma eventual ocupação do Rio de Janeiro. Segundo Paradiso (2005, p. 57), ao tomar esta medida, Zeballos procurava demonstrar que sua política era preventiva, pois garantia ter provas de que era Rio Branco quem planejava um ataque tão logo o programa naval fosse completado.

Os planos de Zeballos foram publicados pelo jornal La Nación (ETCHEPAREBORDA, 1982, p. 40-41), de acentuada oposição ao ministro, despertando reações no Brasil e no Uruguai (BUENO, 2003, p. 258), o que tornou insustentável sua permanência na chancelaria argentina.

Em relação a isso, é salutar o debate promovido por dois estudiosos das relações internacionais argentinas: Roberto Etchepareborda e Miguel Angel Scenna. No trabalho Argentina-Brasil: cuatro siglos de rivalidad, publicados em vários números de Todo es Historia durante o ano de 1973, Scenna analisou as relações entre Argentina e Brasil a partir do desempenho político de Zeballos considerado, por ele, como representante de uma diplomacia agressiva. Defendeu que resultaram deste posicionamento a deterioração das relações bilaterais a ponto de provocar uma guerra entre os dois países e que, portanto, Estanislao Zeballos foi um político primário, agressivo e ingênuo, cuja postura acarretou sérios problemas à Argentina, sobretudo com relação a seu principal vizinho. Etchepareborda, por sua vez, questionou fortemente o trabalho de Scenna e, em 1974, Todo es historia se transformou num locus de debate para estes autores. 
A resposta de Etchepareborda se materializou na obra Zeballos y la política exterior argentina, publicada em 1982, na qual reservou uma parte significativa para responder às críticas tecidas por Scenna. Sustenta que Zeballos nunca pretendeu, de fato, fomentar uma guerra contra o Brasil, ainda que de caráter preventivo e interpreta todo o ocorrido como um ultimátum ao Brasil (ETCHEPAREBORDA, 1982, p. 99), conforme justificativa na carta enviada por Zeballos a Roque Sáenz Peña ${ }^{35}$, em 23 de junho de 1908. Nesse sentido, argumenta que Zeballos propôs uma diplomacia armada para defender os interesses nacionais diante da política de supremacia naval de Rio Branco, cujo intuito era o de conduzir a política na porção sul do continente americano (ETCHEPAREBORDA, 1982, p. 99).

De qualquer maneira, a continuação de Zeballos à frente do ministério havia se tornado insustentável. Sofrendo intensa pressão política, o presidente Figueroa Alcorta lhe propôs que renunciasse ao Ministério das Relações Exteriores e Culto e assumisse, definitivamente, o Ministério da Justiça e Instrução Pública, que já ocupava interinamente. Sentindo-se isolado, Zeballos não aceitou a proposta e comunicou ao presidente sua renuncia ao ministério, em 16 de junho de 1908.

A queda de Zeballos não deve ser considerada, apenas, como resultado de pressões externas, pois havia se indisposto, ao longo de sua carreira, com setores políticos argentinos e, também, de opinião pública ${ }^{36}$, especialmente no tocante aos armamentos. Conforme demonstrou Etchepareborda (1982, p. 48, 51), o próprio Zeballos reconheceu que sua saída do ministério esteve relacionada a intrigas de um círculo pequeno, uma espécie de ministério privado que cercava o presidente Alcorta.

A renúncia de Estanislao Zeballos pode ser compreendida, ainda, como uma alternativa a um conflito armado com o Brasil; nesse sentido, seu afastamento buscou evitar perturbações à paz estabelecida na região. Por outro lado, não significou a interrupção de seus projetos de equilíbrio naval ${ }^{37}$ e, tampouco, pôs fim à tensão entre os dois maiores países sul-americanos que continuavam a alimentar as disputas pela hegemonia na região.

Na $R D H L$ e no diário La Prensa, a atuação política de Zeballos em favor da carreira naval e da aprovação da lei de armamentos no Congresso argentino seguia e se fortalecia e, no final de 1908, já fora do ministério, sua campanha proselitista continuou a exigir que os armamentos fossem divididos entre o Brasil e a Argentina:

\footnotetext{
${ }^{35}$ Sáenz Peña representava a Argentina em Roma.

${ }^{36}$ No meio político a oposição a Zeballos era efetuada, principalmente, pelos seguidores dos ex-presidentes Julio Roca e Bartolomeu Mitre e a campanha pela queda de Zeballos era comandada pelos jornais La Nación, El Diário e El País.

${ }^{37}$ As encomendas navais foram feitas a países adversários. Argentina as fez aos Estados Unidos enquanto o Brasil as fizera à Grã-Bretanha, o que contraria visões simplistas sobre o imperialismo (BUENO, 2005, p. 260).
} 
Si el Brasil ama la paz, si es amigo de la República Argentina, si no se arma para imponérsele en la acción diplomática o militar, concluya en un día, en una hora, la negociación diplomática iniciada por mí, para dividir entre nuestros dos países amigos, su nueva escuadra. Cédanos de una vez un "dreadnought" y algunos otros cascos, ya que reconoció en mayo (1908) cuando temían mi acción -que era posible pactar la equivalencia naval sobre esa base. (ZEBALLOS, 1908, p. 529).

\section{Telegrama número 9}

Por ocasião de sua renúncia, Zeballos já havia afirmado possuir documentos firmados por Rio Branco em que ficava explícita a política agressiva brasileira. Em setembro de 1908, em sua Revista de Derecho, Historia y Letras, o ex-Ministro argentino novamente atacou a política "pacifista" de Rio Branco:

Desgraciadamente los armamentos del Brasil dicen lo contrario y lo dice explicitamente además, la cancilleria de Itamaraty. Su política oficialmente pacifista es mantenida a fin de sugestionar, de uniformar hasta extremos peligrosos para el Brasil mismo, el odio y el ardor bélico del pueblo brasileño contra la República Argentina. (ZEBALLOS, 1908, p. 116).

Afirmava possuir documentos comprometedores, como aquele em que o chanceler brasileiro ordenava a um de seus agentes que

divulgue las pretenciones 'imperialistas' de la República Argentina, haciendo saber en los altos círculos políticos que en su vanidad sueña con el dominio de Bolivia, del Paraguay, del Uruguay y también de nuestro Rio Grande. [...] parte Demuestre que el Brasil, en homenaje a la justicia ampara a los débiles en defensa de sus intereses internacionales, con cuyo proceder humanitario muéstrase conforme la cancillería de Washington. (ZEBALLOS, 1908, p. 116). 
A possibilidade da existência de tais documentos provocou uma grande tensão nas relações diplomáticas não só de Brasil e Argentina, mas também nos países vizinhos e Rio Branco apressou-se a desmentir a informação, alegando nunca ter emitido semelhante documento. Zeballos, por sua vez, por meio de La Prensa, declarou possuir fotografia absolutamente comprovada do documento, cujo teor revelava um plano agressivo de Rio Branco contra a Argentina. Assim, ao denunciar o telegrama, Estanislao Zeballos transmitiu a ideia de que não defendia apenas os interesses argentinos, mas de todas as nações da América do Sul e, ao mesmo tempo, reforçou a necessidade de proteção contra o Brasil, representada pela sanção da lei de armamentos.

Numa atitude desafiadora, propôs que o Barão revisasse seu arquivo secreto do Pacífico e lesse o documento original que lá existia, sob as seguintes chaves: 17 de junho de 1908, às 6 horas e 57 minutos, Número 9; além disso, cogitou a possibilidade de submeter o assunto a um tribunal arbitral, constituído por três ministros plenipotenciários europeus acreditados em Buenos Aires, a serem escolhidos por Rio Branco (BUENO, 2003, p. 264).

O documento secreto a que Zeballos se referia existia e era um telegrama enviado à Legação Brasileira em Santiago (Chile), em 17 de junho de 1908, um dia após a renúncia do ministro argentino, que fora interceptado em Buenos Aires, possivelmente por ordem dele próprio, e decifrado com um conteúdo deturpado. A mensagem foi lida na Câmara de Senadores pelo novo Ministro das Relações Exteriores, Victorino de La Plaza, como prova de uma política brasileira perigosa para a Argentina.

Rio Branco divulgou a chave com que eram cifrados os telegramas reservados do Itamaraty e demonstrou que Zeballos, quando ainda era ministro, interceptou o telegrama número 9 e mandou que fosse decifrado. No entanto, a decifração não correspondeu ao seu teor exato e conferiu um sentido diverso daquele manifestado pelo ministro brasileiro na versão verdadeira. Diante disso, o chanceler brasileiro pediu a Domício da Gama, ministro brasileiro em Buenos Aires, para comunicar ao governo do Chile que o telegrama número 9 havia sido interceptado e falsificado com vistas a enganar o presidente Figueroa Alcorta, seu governo e o Congresso argentino; também solicitou que fosse publicada a cifra, o texto cifrado, letra por letra, a decifração e o texto falso do telegrama nos jornais El Diário, La Nación, El País e La Argentina que o atenderam prontamente, já que engrossavam as fileiras oposicionistas a Zeballos.

Concordamos com a perspectiva aberta por Clodoaldo Bueno (2003, p. 266), de que o incidente do "número 9", embora deva ser debitado à conduta pessoal de Zeballos, não pode deixar de ser visto como um lance da concorrência pelos armamentos, a qual se alimentava na rivalidade entre os dois maiores países do segmento sul-americano. O governo argentino não emitiu nenhuma manifestação formal sobre o incidente nem declarou que as relações entre os dois países tivessem sofrido alguma alteração, outrossim, manteve a discussão da lei de armamentos e a negociação da equivalência naval. 
Zeballos, embora desmoralizado e fora da atuação direta na política externa, continuou sua campanha anti-brasileira por meio da imprensa e da Câmara dos Deputados. Na Revista de Derecho, Historia y Letras publicou, entre setembro de 1908 e maio de 1910, uma série de artigos intitulados "Diplomacia Desarmada"38, nos quais expôs o espírito agressivo do Brasil em relação à Argentina e, em 1912, por ocasião do falecimento de Rio Branco, um texto carregado de críticas ao adversário.

No artigo "Río Branco", esclareceu, desde o início, que a glorificação dos mortos por parte daqueles que os combateram em vida era a maior hipocrisia cometida pelos humanos e que não se renderia a homenagear o Barão, mas sim, a julgar seus atos à luz da história.

Em sua análise, rebateu a ideia amplamente aceita de que Rio Branco era um sábio. Para Zeballos, a atuação brilhante do ministro brasileiro, além de contar com reflexo das glórias de seu pai, o Visconde do Rio Branco ${ }^{39}$, era fruto da habilidade em aproveitar a ocasião. Com a queda do Império, o Brasil apresentava uma política exterior complicada pelo envolvimento em graves questões que ameaçavam suas fronteiras e Rio Branco, familiar a essas questões - devido à colaboração que havia prestado ao Visconde -, entendeu que era sua ocasião:

El primer acierto de Río Branco fué la oportunidad elegida para iniciar su carrera diplomática en el medio desorganizado y vacilante de la República. Tuvo la visión del momento y el dominio perfecto de los hombres que recogian la sabia herencia monárquica. Sabía que para ellos era una providencia el ofrecimiento de sus servicios. Comprometidos los republicanos en las hondas cuestiones de organización general, sin elementos militares y con querellas internacionales peligrosas, la presencia del barón en la arena era, em efecto, una garantía para todos, y motivo de desahogo y de alivio para los repúblicos improvisados de la Revolución. (ZEBALLOS, 1912, p. 415).

O referido texto apresentou dois importantes significados: em primeiro lugar, evidenciou a atuação política de Zeballos em assuntos diplomáticos, mesmo após seu afastamento da pasta; além de que, deve ser encarado como um manifesto em sua própria defesa. Sem mencionar o incidente que envolveu o telegrama número 9 e sua queda do ministério, ressaltou veementemente o caráter defensivo que, de acordo com ele, marcou

\footnotetext{
${ }^{38}$ Cabe destacar que a EUDEBA - editora da Universidade de Buenos Aires -, considerada um símbolo da intelectualidade acadêmica argentina, publicou, em 1974, uma reedição desses textos, mantendo seu título, porém, incorporando um artigo da RDHL de 1912, assinado pelo próprio Zeballos, por ocasião da morte do Barão do Rio Branco.

${ }^{39}$ José Maria da Silva Paranhos, Viscondedo Rio Branco, foi um político, monarquista, jornalista e diplomata brasileiro.
} 
sua atuação na chancelaria. A política desenvolvida por Rio Branco foi apresentada como manipuladora, já que teria forjado um "perigo argentino" sob o pretexto de não encontrar empecilhos a sua militarização; além disso, acusou o governo brasileiro de tentar incutir a noção de que a Argentina representava uma ameaça iminente para que o Itamaraty aparecesse, diante da opinião pública brasileira, como o "salvador da pátria".

Segundo Zeballos, o plano do ministro brasileiro consistia em:

formar una gran masa de opinión, de diplomacia y de poder militar sudamericano, que rodeando a la República Argentina la aislara bajolas inspiraciones de Itamaraty. Los Estados Unidos, la conquista de su apoyo moral o por lo menos de su prescindencia, formaban capítulo en el plan. (ZEBALLOS, 1912, p. 430).

Manifestou que, embora o governo brasileiro negasse, a Argentina conhecia esse plano desde 1904 e que seu fracasso se deveu ao fato de Rio Branco ter menosprezado o adversário por imaginar que poderia dar à Argentina o mesmo tratamento dispensado pelo Brasil a outros países de menor importância na região. Em outras palavras, Zeballos buscou uma inversão de papéis, salientando que aqueles que se referiram ao chanceler brasileiro como pacifista, conciliador, justo e contrário à conquista, esconderam profundas contradições e ironias; e que a política argentina, apesar de julgada como imperialista e a gressiva, agiu de forma preventiva e defensiva ${ }^{40}$.

Zeballos (1912) terminou seu texto ponderando que, naquele momento, Brasil e Argentina viviam um ponto de evolução internacional, que os argentinos não alimentavam ódio pelo Brasil, assim como seus homens de Estado não tinham planos que ameaçassem a soberania; contudo, criticou a aproximação do Brasil com os Estados Unidos. Seu intuito era o de selar a amizade entre os países vizinhos, o que entendemos como algo importante diante da ampliação da zona de influências norte-americana sobre o continente.

Estanislao Zeballos foi um aguerrido adversário de Rio Branco. Durante três décadas a opinião pública argentina anti-brasileira foi influenciada por ele, aguçando a rivalidade entre os dois países. Todavia, diante da morte do ministro brasileiro, afirmou:

40 Advertiu, ainda, que pretendia publicar documentos da chancelaria que poderiam provar à História, de forma irrefutável, que a política argentina foi pacífica, conciliadora, prudente, de previsão defensiva e de desarme continental. Gostaríamos de ressaltar que tais documentos nunca foram publicados. 
He tenido el honor de ser adversario resuelto e irreductible de la política del barón de Río Branco, pero jamás de su persona, cuyos talentos me hice siempre un honor en respetar. Le debo intensa gratitud, porque su obsesión llegó hasta el extremo de encarnar en el alma brasileña dos nombres, como los dos principios igualmente eternos, del Bien y del Mal: el suyo y el mío. (ZEBALLOS, 1912, p. 438).

Tanto Rio Branco, como Zeballos, tiveram a pretensão que o seu país conquistasse a hegemonia na América do Sul e, para isso, procuraram enfraquecer e "desconstruir" o adversário. Com Zeballos afastado, ao menos oficialmente, das questões políticas externas, as relações bilaterais entre Brasil e Argentina passaram gradualmente para um período de distensão. Em 1912, diante da influência norte-americana na região, o discurso havia sido transformado e as ideias de uma aproximação da Argentina com relação ao Brasil foram revisitadas por Zeballos que, por meio de sua Revista, ecoava a vontade de que esta aproximação pudesse ser protagonizada pelos dois maiores adversários sul-americanos, ele próprio e o Barão do Rio Branco.

\section{Referências}

BANDEIRA, Moniz. A presença dos EUA no Brasil: dois séculos de história. Rio de janeiro: Civilização Brasileira, 1973.

. Política Externa da Primeira República: os anos de apogeu (de 1902 a 1918). São Paulo: Paz e Terra, 2003.

BUENO, Clodoaldo. Política externa na Primeira República. Os anos de apogeu (de 1902 a 1918). São Paulo: Paz e Terra, 2003.

DE MARTINI, Fernando Ribas. Toneladas de diplomacia num mar sem fronteiras: discussões sobre os poderes navais de Argentina, Brasil e Chile no início do século XX. Antíteses, Londrina, v. 7, n.13, p. 309-332, jan./jun., 2014.

ETCHEPAREBORDA, Roberto. Zeballos y la política exterior argentina. Buenos Aires: Pleamar, 1982. 


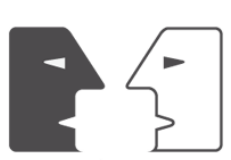

ANTÍTESES

FAUSTO, Boris; DEVOTO, Fernando. Brasil e Argentina. Um ensaio de história comparada (1850-2002). São Paulo: Editora 34, 2004.

INGENIEROS, José. Sociología argentina. Buenos Aires: Editorial Tor, 1956.

MUÑOZ, Luciano da Rosa. A política externa de Rio Branco e a Argentina: aproximação no subsistema sul-americano e afastamento no sistema sul-americano e afastamento no sistema internacional (1902-1912). 2010. Dissertação (Mestrado em Relações Internacionais) Universidade de Brasília, Brasília, 2010.

NETO, José Miguel Arias. A Marinha Brasileira no inicio do século XX. Antíteses, Londrina, v.7, n.13, p. 84-112, jan./jun. 2014.

ORTIGUEIRA, Roberto. Zeballos y la política exterior de Chile. Buenos Aires: Librería Clasica, 1993.

PARADISO, José. Um lugar no mundo. A Argentina e a busca de identidade internacional. Rio de Janeiro: Civilização Brasileira, 2005.

PAREDES, Rogelio. Estanislao Zeballos canciller: entre la diplomacia colonial y la guerra moderna (1878-1908). In: FERNANDÉZ, Sandra; NAVARRO, Fernando (Org.). Scribere est agere. Estanislao Zeballos en la vorágine de la modernidad argentina. Rosário: Quinta Pata \& Camino Ediciones, 2011. p. 105-122.

TERÁN, Oscar. Historia de las ideas en la Argentina. Diez lecciones iniciales, 1810-1980. Buenos Aires: Siglo Veintiuno editores, 2009. p. 113-114.

ZEBALLOS, Estanislao. Los armamentos navales del Brasil. Revista de Derecho, Historia y Letras, t.20, p. 289-300, 1904.

. Mitre. Revista de Derecho, Historia y Letras, t. 24, p. 78-95, 1906.

. Resurgimiento cívico. El alma argentina. Revista de Derecho, Historia y Letras, t. 31, p. 301-303, 1908a.

. Diplomacia desarmada. Revista de Derecho, Historia y Letras, t.31, p. 107-134, 1908.

ZEBALLOS, E. Campos Sales. Revista de Derecho, Historia y Letras, 1900a, t. 8, p. 139

ZEBALLOS, E. La palabra de los presidentes. Revista de Derecho, Historia y Letras, t.8, p. 157$158,1900 \mathrm{~b}$.

ZEBALlOS, E. Río Branco. Revista de Derecho, Historia y Letras, t. 41, p. 411-439,1912 . 


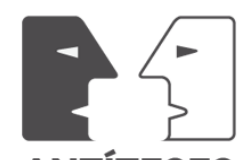

ANTÍTESES

ZIMMERMANN, Eduardo A. Racial ideas and social reform: Argentina, 1890-1916. Hispanic American Historical Review, v. 72, n. 1 p. 23-46, Feb., 1992.

_. _ _ _. Los intelectuales, las ciencias sociales y el reformismo liberal: Argentina, 18901916. Desarrollo Económico, v. 31, n 124, p. 545-564, jan.-mar., 1992.

Recebido em 31/03/2017

Aprovado em 26/06/2017 